\title{
Impact of rewards system in employee's motivation in the organizational context: A quantitative study of manufacturing industry in UAE
}

\author{
Ghazi Rehman A. Din ${ }^{1}$ Noor U. Nisa Shahani ${ }^{1} \mid$ Muhammad Nawaz Baloch*2 \\ 1. Faculty of Business \& Management Sciences, Bath Spa University, United Arab Emirates (UAE). \\ 2. Department of Management Sciences, University of Sindh, Laar Campus, Badin, Sindh, Pakistan. \\ * Correspondence Emails: mnawaz@usindh.edu.pk | m.nawazbaloch010@gmail.com
}

\begin{abstract}
This research aims to investigate the effect of reward systems on the extrinsic and intrinsic motivation of the employees working in various manufacturing companies located in the UAE. In this era of competition, motivated employees considered as a valuable assets and motivation play vital role in productivity and enhancement of job commitment and reduce job turnover intention. While, researchers highlight the significance of reward system to intrinsic and extrinsic motivation in various context. However, this area of research is under-theorized particularly within the UAE context in the food and beverage sector. The data was gathered from 100 respondents through a self-administered survey using a 7-point Likert scale. The data was later analyzed using SPSS. A variety of statistical procedures have been carried out to figure out the reliability and validity of the research hypotheses. Based on the results generated through these statistical procedures, key conclusions and inferences have been drawn. In essence, the organization must take an effective measure that is aimed at enhancing the motivation levels of their workforce. Moreover, a motivated workforce will be more committed and dedicated to achieving the organizational goals and objectives.
\end{abstract}

Article History

Received:

January 3, 2021

Last Revised:

April 13, 2021

Accepted:

April 16, 2021

Published:

April 19, 2021

Keywords: motivation, intrinsic motivation, extrinsic motivation, job satisfaction, job commitment, Self-Determination Theory (SDT), Maslow's Hierarchy of Needs.

How to Cite: Din, G. R. A., Shahani, N. U. N., \& Baloch, M. N. (2021). Impact of rewards system in employee's motivation in the organizational context: A quantitative study of manufacturing industry in UAE. Liberal Arts and Social Sciences International Journal (LASSIJ), 5(1), 105-122. https://doi.org/10.47264/idea.lassij/5.1.8

Publisher's Note: IDEA PUBLISHERS (IDEA Journals Group) stands neutral with regard to the jurisdictional claims in the published maps and the institutional affiliations.

Copyright: (C) 2021 The Author(s), published by IDEA PUBLISHERS (IDEA Journals Group). This is an Open Access article published under the Creative Commons Attribution-NonCommercial 4.0 International License (http://creativecommons.org/licenses/by-nc/4.0/) 


\section{Introduction}

One of the greatest challenges for the manager to keep their staff motivated and committed. Reward system emerged as a powerful tool to create and enhance motivation among employees. Recent evidence suggests that reward system can trigger motivation. However, there is scarcity of research in this area particularly with UAE context. This research paper has investigated the relationship between reward systems and employee motivation within business organizations. Furthermore, this research aims to examine the impact of reward systems on employee intrinsic motivation, to analyze the impact of reward systems on employee extrinsic motivation, and to explore the importance and effectiveness of reward systems on employee motivation in the organization. This paper is organized into literature review, details about the research methodology, results and analysis, discussion and findings, and conclusion sections.

\subsection{Theoretical significance}

Ismail and Ahmed (2015) also suggested that there is a need for further research to understand the reward system and motivation relationship in a UAE context According to various researchers, there is limited research done on reward systems of both intrinsic and extrinsic motivation on employee performance within UAE Context. Also, after thorough research, it has been observed that the literature on the food and beverages industry is scarce. The researches have been done on the hotel industry and other such industries, but fewer studies have been conducted on the food and beverages sector in the light of reward and motivation. Therefore, this study has been conducted to enrich the literature and contribute to enhancing the knowledge of the readers so that the topic could be understood with in-depth information based on the primary data.

\subsection{Practical significance}

With the increasing competition in the business world, the efforts of the organizations to achieve the desired goals and objectives so that competitive advantage could be achieved. Organizations are finding ways to keep their employees motivated so that maximum productivity and performance could be attained. The growth and survival of the organizations are dependent on the employees. Employee motivation plays an important role and this could be enhanced if proper rewards are offered to them. The present study was carried to determine the influence of reward systems i.e., intrinsic reward and extrinsic reward on employee motivation. This study would be beneficial for the management of the food and beverages industry and other industries too, as it would explain the importance of a reward system in boosting the employee motivation level. Implementation of intrinsic reward and extrinsic reward would bring about positive outcomes for the organizations as well as the employees.

\section{Literature review}

In this highly competitive business environment, it has become quite crucial for organizations to keep their human capital motivated (Raghavendra \& Vijayakumar, 2020). The. Furthermore, the way organizations treat their employees has a greater impact on the growth and survival of the organization (Karell \& Widlund, 2019). Strategies are being derived by the organizations to establish a balance between the influence of individuals on the organization and the influence of the organization on the employees. It means that whatever you give to the employees, it always returns in some way or the other. Considering this, organizations have to understand 
the importance of employee motivation to attain high-level employee performance (Asseburg \& Homberg, 2020).

The motivation could be categorized into two types i.e., Intrinsic Motivation and Extrinsic Motivation (Ryan \& Deci, 2020). The innate interest in experiencing the pleasure and satisfaction in doing a task is termed an intrinsic motivation. The employees who are high in intrinsic motivation feel pleasure in conducting a task without expecting anything material in return (Pink, 2011). On the other hand, the extrinsic motivation in an employee directs him/her to perform a task for the external reasons to attain rewards and avoid any undesired results (Ryan \& Deci, 2020).

\subsection{Reward system}

The reward is a benefit that is given by the employers in the form of money/cash, benefits, or promotion and drives satisfaction from the job like the feeling of accomplishment, pride in work of an employee, and/or being a team member. A higher level of satisfaction is produced as a result of rewards, and reward enables an employee to make things/tasks done (Bintoro \& Daryanto, 2017).

A study was conducted by Chepkemoi and Bett (2018) in a manufacturing company. The study aimed to understand the reward strategy and the engagement of employees. It was found that the organization offers appreciation after every six months. In addition to this, the employees are provided with training, annual benefits, and club membership, which allows the employees to be engaged in the organization and enhanced their motivation and satisfaction. Similarly, a study conducted by Arokiasamy et al. (2013) on the employee motivation in academic setting. It was revealed that an effective reward system has direct relationship with staff motivation and satisfaction. This shows that the reward system posits many effects in the organization, and its effective management can lead to positive outcomes as the goals of the organizations are achieved.

\subsubsection{Intrinsic reward}

Shamir (1991) noted that the intrinsic reward is derived from the activity performed. Shamir (1991) also argued that people can help others to boost their mood. Furthermore, according to Williams and Shiaw (1999), the citizenship behaviours can be displayed to reduce anxiety. Nawaz et al. (2017) found the role of rewards in citizenship behaviours within a higher educational context.

According to O'Reilly (1991), intrinsic rewards are present in the job and helps in providing personal satisfaction to employees, e.g., reputation empowerment, autonomy, trust, expense preference, etc. The author added that intrinsic rewards are essential to maximizing employee commitment, motivation, and involvement in the organization which is triggered by employee satisfaction. The personal needs of the employees are satisfied with the help of intrinsic rewards by effectively managing these rewards for the employees (Frey \& Jegen, 2001). Intrinsic rewards aim to provide enjoyment and pleasure for the employees. Goal theory states that intrinsic rewards posit better results and high productivity as compared to extrinsic rewards (Wright, 2007). According to O'Driscoll and Randall (1999), the intrinsic rewards help in better organizational support and employee satisfaction that enhances affective commitment and job involvement. 


\subsubsection{Extrinsic reward}

The extrinsic rewards are external to the job, and they involve fringe benefits, pay/cash, job security, private office portion/area, timely promotions, and social climate (Herzberg, 1987; Nelson, 1994; O'Driscoll \& Randall, 1999). Some other examples that are included in the extrinsic rewards are the merit bonuses, pay raises, salary, vacation payment, paid leaves, etc. This shows that the extrinsic rewards are tangible. The employees get motivated by these kinds of rewards and failure to receive the results in disappointment for them. Hence, when their motivation to do the given task decreases, so does their performance and productivity, which affects the organization.

The employees who prefer extrinsic reward over intrinsic reward tend to show higher performance and contribute to achieving the goals of the organization when they receive tangible rewards or extrinsic rewards (Newman \& Shaikh, 2012). Extrinsic rewards show reciprocity results, as when it is received the employees are satisfied which boosts their performance and in return benefits the organization (Mantere, 2007). This shows that extrinsic motivation leads to better performance of the employees. According to Sharma (2019), extrinsic rewards increase the efforts of the employees at the job as they are internally motivated. They put up all their efforts to complete the task successfully. The organization ultimately benefits from it in the long run.

\subsection{Employee motivation}

According to the definition of Sajjad et al. (2013), motivation is a reason that enables the individual to show certain behaviour. Likewise, motivation is a driving force that moves the employees to achieve the goals of the organization. Armstrong (2001) stated that motivation is a tool or factor that impacts the individuals to act in a particular expected manner. $\mathrm{He}$ categorized it into three aspects, the first is working environment/condition, the second is jobrelated matters e.g., working tools and availability of resources and the third is personal matters that include opportunities for growth, promotions, and training. There are two types of motivation according to self-determination theory (Fernet et al., 2012). The autonomous motivation that deals with the employee free will to do the task as he/she feels inner satisfaction to do so. The other category is controlled motivation that is used under external or internal force so that a task is completed to avoid feelings of guilt.

In manufacturing firms, the role of motivation is quite important (Jaśkiewicz \& Nowak, 2019). It is because the resources are scarce and time duration is limited, so in this case, the employees need constant motivation to cope up with stressful situations (Sureephong et al., 2020). Quality matters a lot in such firms, and the customers only buy the products if they find them of high quality (Kaplan, 2017). This could be achieved if quality standards are met which is done with the help of motivated employees. The low motivation of employees could lead to low quality of products, hampering the reputation of the firms (Bintoro \& Daryanto, 2017). The organizations should motivate the employees so that they can better cope up with the situation and helps to achieve the goals of the organization.

\subsubsection{Rewards and employee intrinsic motivation}

Motivation is derived with the help of the intrinsic factors e.g., a simple 'well-done' from the manager or any supervisor could be beneficial for the employees' motivation and positive 
outcomes of the organization (Jansen et al., 2019). Whether the motivation is intrinsic or extrinsic, they have to be fairly distributed without any kind of bias, then the motivation increases (Ajayi, 2019).

In almost every industry, the motivation of employees is required. It is a great challenge for the organizations to figure out the best possible motivator for the employees so that the productivity and performance of the employees could be maximized (Kubota, 2019). In manufacturing firms, motivation has immense importance too (Kokubun, 2018). Motivation could be enhanced with the help of intrinsic rewards as the employees would feel that the organizations are valuing their efforts (Sharma, 2019). It enhances the intrinsic motivation of the employees. Also, this encourages the employees to do better in the next tasks (Ahmed, 2019). Also, according to Chen et al., (2016), intrinsic motivation in manufacturing firms ultimately helps the employees to encourage them so that they can do their best. In this way the employees and the organization, both are benefited. The foregoing discussion suggested an impact of reward on intrinsic motivation; thus, we proposed the following hypothesis within the UAE context.

\section{H1: Reward has a positive impact on employee intrinsic motivation}

\subsubsection{Rewards and employee extrinsic motivation}

Extrinsic motivation is external to the job, and they involve fringe benefits, pay/cash, job security, private office portion/area, promotions, and social climate (Herzberg, 1987; Nelson, 1994; O'Driscoll \& Randall, 1999). Financial rewards help to motivate employees but in the long run, they may not be that effective as employees would start taking it for granted (Malik et al., 2019). Money is not considered a good motivator, but not giving it at all may show negative results in the organization (Clarity-Wave, 2019). The employees who value extrinsic rewards would feel motivated as they receive them from the organization (Vouzas \& Katsogianni, 2018). This increases their level of extrinsic motivation. A study was conducted on the service sector, and the result of the study revealed that employees feel more motivated by extrinsic rewards than intrinsic ones, which helps in boosting the extrinsic motivation of the employees. The reward system should be fair, only then the employees could feel motivated (Ngwa et al., 2019). Managers have to take care of the rewards i.e., at what time, in which situation, and to whom the financial reward is to be given (Okello, 2018). If this is not done in the right way, the organization may have to face loss due to high expense and high cost of the employees. The foregoing discussion suggested an impact of reward on intrinsic motivation; thus, we proposed the following hypothesis within UAE context

\section{H2: Reward has a positive impact on employee extrinsic motivation}

\section{Underpinning the theories}

The study has used the Maslow's theory of Hierarchy of Needs and the Self-Determination Theory as follows:

\subsection{Maslow's hierarchy of needs}

This theory is related to the needs of an individual. It has following five stages: 
a) Physiological needs - Food, water, shelter

b) Safety needs - Employment, resources, personal security, property, health

c) Social needs - Family, friendship, intimacy, sense of connection

d) Esteem needs - Self-esteem, respect, status, strength, recognition, freedom

e) Self-actualization - Desire to become the most that one can be and it includes an ability of an individual to understand his/her talent and objectives.

De-Vito et al. (2016) noted that in any organization depending on hierarchy of needs, employees can be motivated intrinsically or extrinsically by a reward system. Furthermore, a reward system motivates employees in their promotions and professional development. Similarly, Kalhoro et al. (2017) discussed the hierarchy of need theory and its role in the motivation of banking employees.

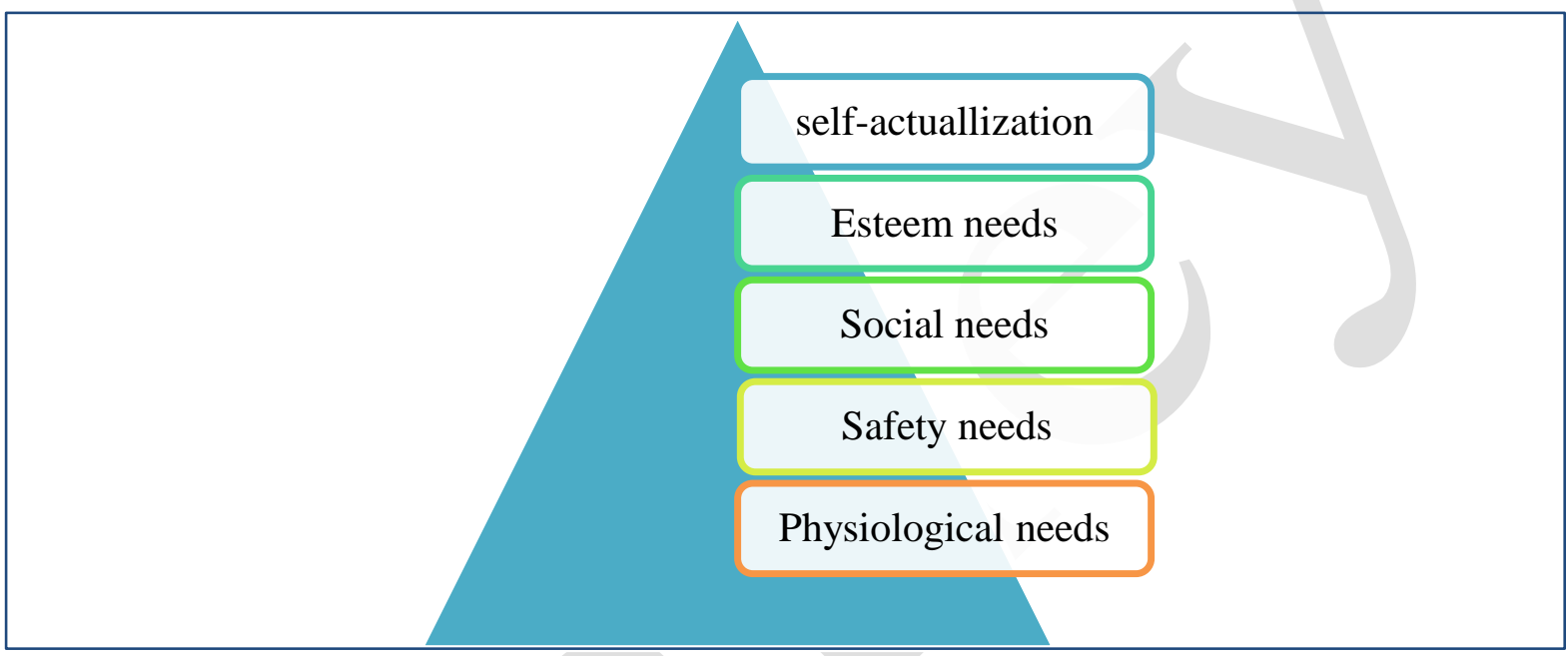

Figure 1: Maslow's Hierarchy of needs

\subsection{Self Determination Theory (SDT)}

According to the Self-Determination Theory (SDT), motivation could be categorized into two types i.e., Intrinsic Motivation and Extrinsic Motivation (Ryan \& Deci, 2020). The innate interest in experiencing pleasure and satisfaction in doing a task is termed intrinsic motivation. The employees high in intrinsic motivation feel pleasure in conducting a task without expecting anything material in return (Pink, 2011). The extrinsic motivation in an employee directs $\mathrm{him} / \mathrm{her}$ to perform a task for external reasons to attain rewards and avoid any undesired results (Ryan \& Deci, 2020).

\subsection{Proposed hypotheses}

The forgoing debate in literature review section has revealed that there may be a positive impact of reward system on intrinsic and extrinsic motivation of the employees. To test this impact, we have proposed the hypotheses $\mathrm{H} 1$ and $\mathrm{H} 2$ :

H1: Reward system has a positive impact on intrinsic motivation

$\mathrm{H} 2$ : Reward system has a positive impact on extrinsic motivation 


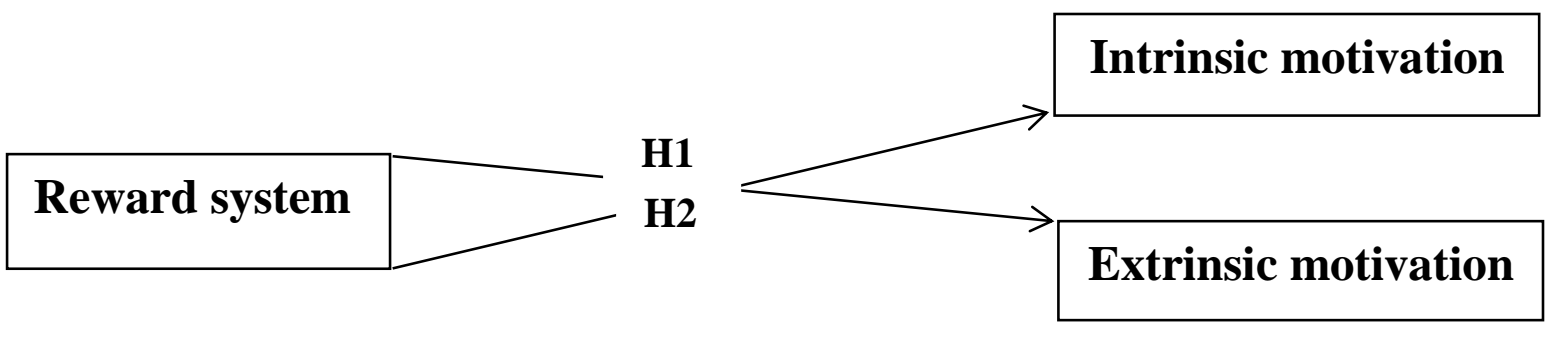

\section{Research methodology}

\subsection{Research design}

The target population involved is the employees that are working in various manufacturing companies in the U.A.E. The target population includes employees belonging to both genders i.e., male and female. This study used the random sampling technique. Furthermore, Roscoe's Rule of Thumb was used to determine the sample size for this study. Roscoe (1975) posited that a sample size of more than 30 and less than 500 is considered to be acceptable and sufficient for most research studies. Bearing in mind the associated time and cost constraints, a sample size of 100 individuals was used for this study. For this study, a cross-sectional time horizon was adopted in which the data was collected at one point of time only.

\subsection{Instrument development}

As mentioned above, this research is quantitative and uses statistical techniques to analyze and present data. Keeping this in mind, a close-ended instrument was adopted to extract responses from the study participants. A 7-point Likert Scale was used to capture the responses. On the other hand, it is equally important to select reliable questionnaires to ensure the reliability and credibility of the research. It should be ensured that the selected questionnaire is aimed at accurately measuring the variables of the study. For this study, the questionnaires were developed from the work of Ryan and Deci (2020) and Tremblay et al. (2009).

\subsection{Data collection and analysis}

Researchers distributed the adopted scale through a survey questioner. Moreover, participants were requested to respond. Researched utilized SPSS for data analyses. Several tests were conducted to determine and check the validity and reliability of the research hypotheses and questions. These tests included: reliability, descriptive, normality, correlation, and regression (ANOVA) tests. The results of data analysis have been presented in the succeeding chapter.

\section{Data analysis and results}

The results and analysis of the data has been categorised in demographic, reliability, descriptive, and regression analyses as follows:

\subsection{Demographic analysis}

A demographic analysis aids in understanding and examining the individual characteristics. The researcher can examine as many characteristics as may be deemed fit for the understated research purposes. These individual characteristics may include gender, income levels, 
education, marital status, professional experience etc. For this study, the individual characteristics that have been analyzed include gender, qualification, experience, and organizational level. A demographical analysis of the respective genders highlights that 39 male respondents participated in this study and constituted $39 \%$ of the sample size. It is pertinent to mention that high female participation was witnessed as compared to the males. 61 females agreed to take part in this research study. The female population constituted $61 \%$ of the total sample size.

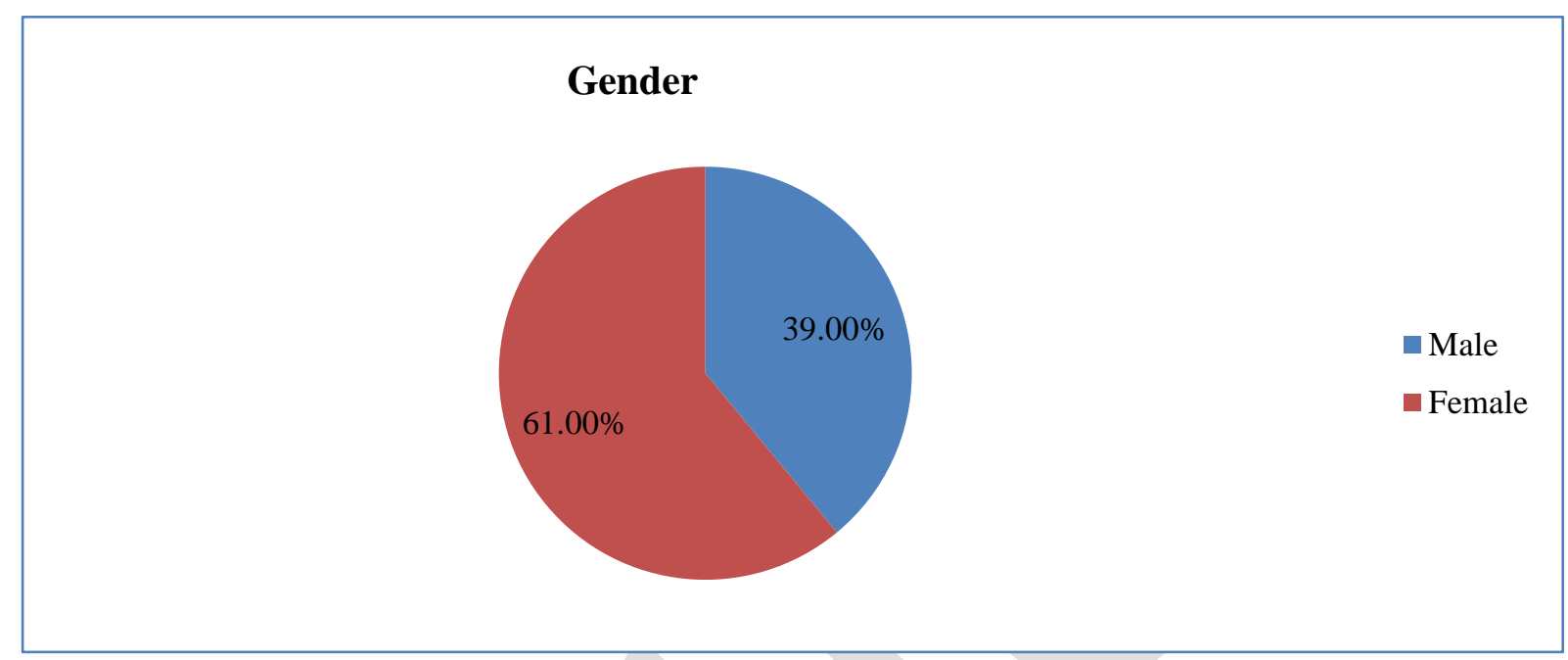

Figure 2: Gender of the respondents

A demographic analysis of the respective qualifications of the study participants reveals that 7 participants had a below $12^{\text {th }}$-grade education. 28 undergraduate participants were a part of this study and consumed $28 \%$ of the total sample. The postgraduates were the highest in frequency with a tally of 58. They consumed a sizeable 58\% of the entire research sample. On the other hand, 7 participants possessed some diploma certifications in various domains.

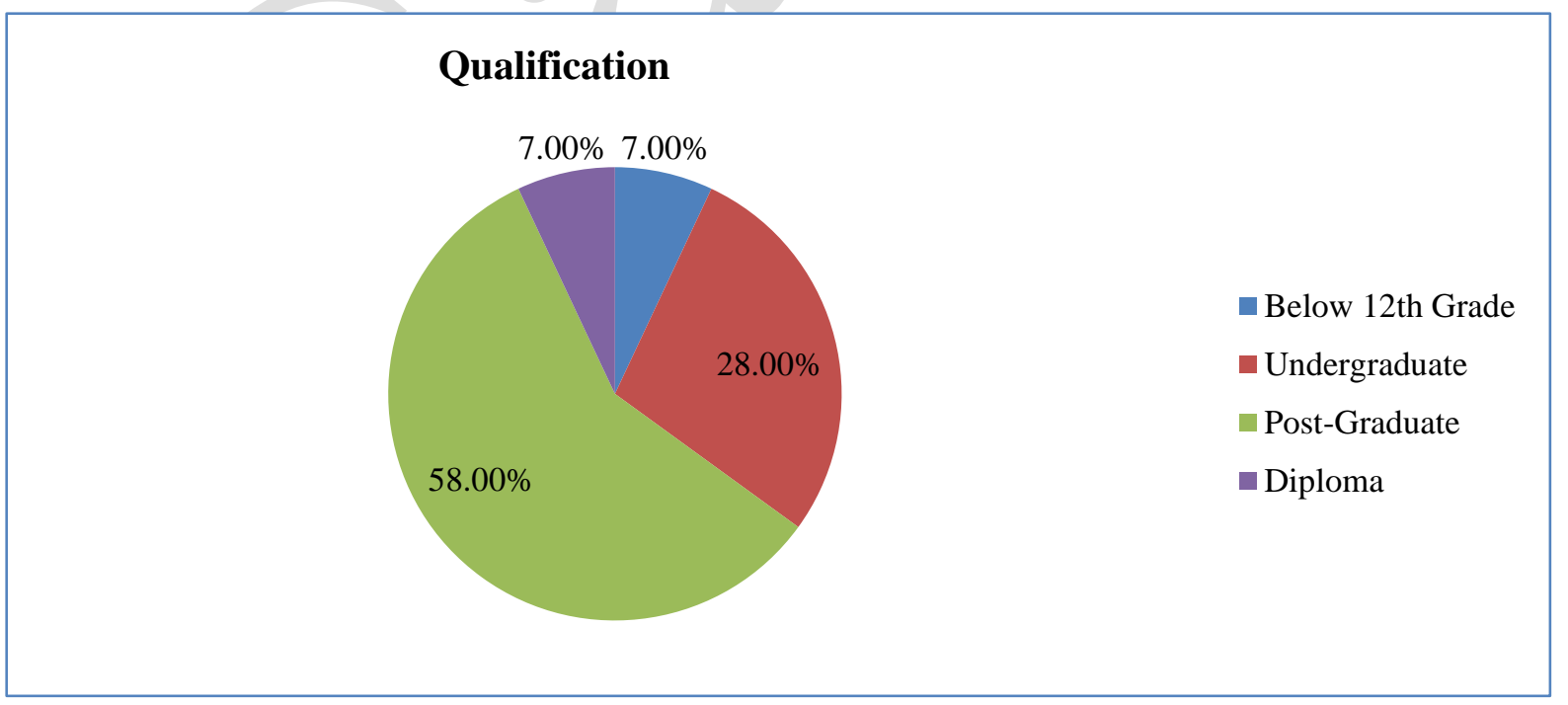

Figure 3: Qualification of the respondents

The professional experiences of the participants of the study have also been analyzed and presented. It can be observed that $27 \%$ of the respondents possessed a professional experience 
of 1 to 5 years. A similar percentage of the participants were those who possessed an experience of work of 5 to 10 years. A majority of the participants (i.e., 40\%) had experience of work ranged between 10-15 years, whereas, only $6 \%$ of the respondents had the experience of work of more than 15 years. Therefore, it can be seen that $54 \%$ of the research sample had the experience of work ranged from 1 form 10 years and $46 \%$ had experience ranging between 10 to $15+$ years.

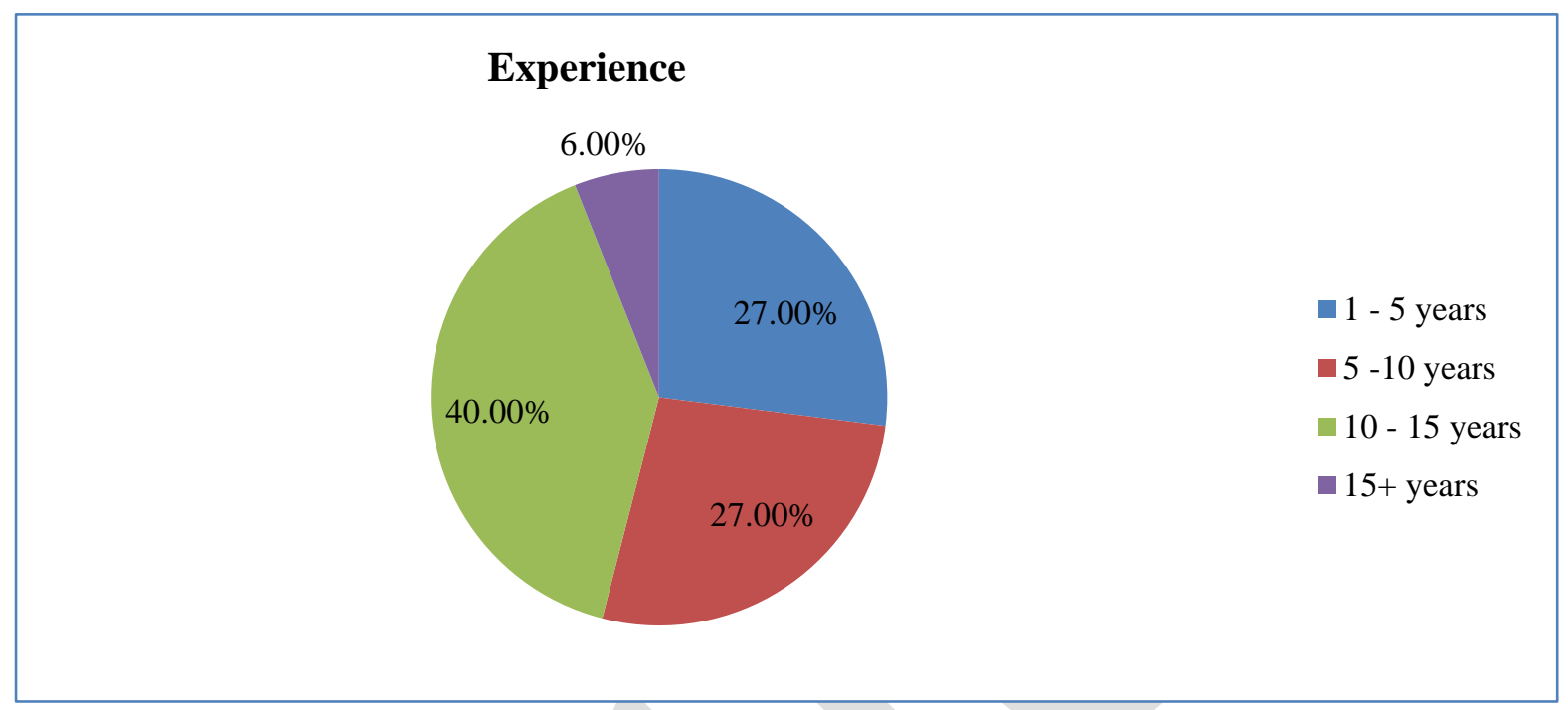

Figure 4: Experience of the respondents

The participants were asked to reveal the level of management in which they worked. It can be observed that 14 employees/participants worked in a non-management position. Eighteen respondents were working in the lower management levels of their organizations. A majority of the respondents (i.e., 49\%) were those who were working in the middle-level management positions of their respective organizations, whereas, $19 \%$ of the participants were involved in top-level management positions. A major portion of the research sample was composed of middle-level management employees whereas; the non-management participants were the lowest in number.

\section{Level of organization}

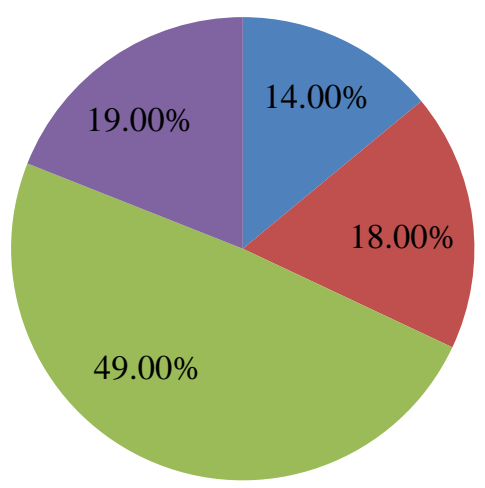

non-management

- lower management

middle management

- top management

Figure 5: Level of organization of the respondents 


\subsection{Reliability analysis}

A reliability analysis is an important statistical procedure that tells the validity and reliability of the instruments that have been adopted to measure the study variables. Reliability tells the researcher regarding the level or degree of internal consistency in between the items of variables. In essence, it tells whether the research instrument adopted against a particular variable is indeed measuring that variable or not. The Cronbach Alpha value is the measure of reliability that shows the degree of internal consistency in between the items of the research instruments. A Cronbach value of more than 0.05 is accepted according to most researchers.

The table-1 shows the study variables along with their respective instrument items and the Cronbach Alpha value. The reward system is the independent variable and intrinsic and extrinsic motivation is the dependent variables. It can be observed that the instrument adapted to measure reward systems had a total of 5 items with a Cronbach Alpha value of 0.848 . The instrument adopted against intrinsic motivation had a total of 3 items with a Cronbach Alpha value of 0.734 whereas; extrinsic motivation also had 3 items with a Cronbach Alpha of 0.808 .

Table-1: Reliability analysis

\begin{tabular}{lcc}
\hline Variables & No. of items & Cronbach Alpha $(\alpha)$ \\
\hline Reward system & 05 & .848 \\
Intrinsic motivation & 03 & .734 \\
Extrinsic motivation & 03 & .808 \\
\hline
\end{tabular}

\subsection{Descriptive analysis}

A descriptive analysis is a statistical technique that depicts the mean or average responses that have been obtained against each of the under-observation variables. The standard deviation is a measure that talks about the data that how much it is dispersed from the mean or average value of the data. On the other hand, to know the normality skewness and kurtosis have been used. If the data is skewed i.e., not evenly distributed, it means that it is not normal and hence not fit for regression. The normal acceptable value for skewness and kurtosis is -1 to +1 and 3 to +3 .

The table-2 depicts the means, standard deviation, and the skewness and kurtosis values that have been obtained against each of the variables. A 7-point Likert scale was used in which 1 indicated: strongly disagree, 2: disagree, 3: somewhat disagree, 4: neither disagree nor agree, 5: somewhat agree, 6: agree and 7: strongly agree. It can be observed that Reward Systems (RS) had a mean of 5.11 which indicates that the average response was more towards the "agree" option. The value of standard deviation is also within the acceptable range. The skewness and kurtosis values are also acceptable. Intrinsic Motivation (IM) has a mean value of 5.37 which again indicates that the average response was bent towards the "agree" option on the 7-point Likert scale. Likewise, Extrinsic Motivation also had a mean of 5.15. Both of these variables had similar standard deviations. The skewness and kurtosis value have also been observed to be within the acceptable ranges. Two things can be deduced from the data given above. Firstly, the mean responses against all of the variables are above 5 meaning that the average responses were tilted towards the "agree" option. Secondly, the skewness and kurtosis values against all of the variables are in ranges that are accepted indicating the normality of the data and thus perfect for regression. 
Table-2: Descriptive analysis

\begin{tabular}{ccccc}
\hline & Mean & Std. deviation & Skewness & Kurtosis \\
\hline RS & 5.1120 & 1.03955 & -.783 & 1.307 \\
IM & 5.3767 & .95658 & -.866 & 1.034 \\
EM & 5.1567 & .99770 & -.211 & .851 \\
\hline
\end{tabular}

A technique used to figure out the significance, magnitude, and direction of the association between the variables is known as correlation analysis. To do the correlation analysis of the present study, Pearson Correlation (PC) has been used. It can be seen that the Reward Systems (RS) and Intrinsic Motivation (IM) are significantly correlated. A correlation of more than 0.50 is considered to be strong. The correlation between RS and IM has been recorded at 0.722 which means that these two variables are strongly and positively correlated. The Reward Systems (RS) and Extrinsic Motivation (EM) are also significantly correlated at a 99\% confidence level. The correlation between these two variables has been observed at 0.706 which is again strong and positive. Likewise Intrinsic Motivation (IM) and Extrinsic Motivation (EM) are also significantly and positively correlated as the correlation value has been recorded at 0.653 .

Table-3: Correlation analysis

\begin{tabular}{ccccc}
\hline \multicolumn{5}{c}{ Correlations } \\
\hline \multirow{2}{*}{ RS } & RS & IM & EM \\
& Pearson correlation & 1 & & \\
& Sig. (2-tailed) & & & \\
IM & N & 100 & & \\
& Pearson correlation & $.722^{* *}$ & 1 & \\
& Sig. (2-tailed) & .000 & & 1 \\
EM & N & 100 & 100 & \\
& Pearson correlation & $.706^{* *}$ & $.653^{* *}$ & 100 \\
\hline **. Correlation is significant at the 0.01 level (2-tailed) & .000 & \\
\hline
\end{tabular}

\subsection{Regression analysis}

\subsubsection{Regression between Rewards System and Intrinsic Motivation}

The regression analysis is one of the most important statistical procedures that trace the influence of IV onto the DV. A regression analysis reveals the effect of a change of 1 unit in the IV onto the DV. Regression is usually conducted in such circumstances when two variables are associated with each other in such a manner that a certain change in the former leads to a significant and noticeable difference in the latter. Since our study includes one independent variable (i.e., Reward Systems) and two dependent variables (i.e., extrinsic and intrinsic motivation), a regression analysis will aid in determining the nature of the relationship between these variables.

The table no. 4 and 5 portrays that the regression analysis results undertake to determine the validity of our first hypothesis, H1. The first hypothesis posited a relationship between Reward Systems (RS) and Intrinsic Motivation (IM). The table shows the fitness value or F value that 
came out to be 106.521 which is greater than 4.00. A fitness value of more than 4.00 indicates that our proposed model is fit. The variance from the $\mathrm{R}$ square value which is $0.521 \mathrm{can}$ be seen. It means that a variance of $52.1 \%$ is observed in the DV due to the IV. The significance value has been recorded at 0.000 . This value is less than the threshold value of 0.05 . The significance of the results can be seen from this value. The value of Beta indicates that a oneunit change in Reward Systems (RS) will lead to a 0.722 unit increase in Intrinsic Motivation (IM). It means that a direct positive linkage exists for Reward Systems and Intrinsic Motivation. This finding is supportive of the proposed hypothesis. Consequently, the first hypothesis, $\mathrm{H} 1$ is accepted.

Table-4: Regression analysis of rewards system and intrinsic motivation

\begin{tabular}{|c|c|c|c|c|c|}
\hline \multicolumn{6}{|c|}{ Coefficients $^{\mathrm{a}}$} \\
\hline \multirow[t]{2}{*}{ Model } & \multicolumn{2}{|c|}{ Unstandardized coefficients } & \multirow{2}{*}{$\begin{array}{l}\text { Standardized } \\
\text { coefficients } \\
\text { Beta } \\
\end{array}$} & \multirow[t]{2}{*}{$\mathrm{t}$} & \multirow[t]{2}{*}{ Sig. } \\
\hline & B & Std. error & & & \\
\hline \multirow{3}{*}{$\begin{array}{lc}1 & \text { (Constant) } \\
\text { RS }\end{array}$} & 1.982 & .336 & \multirow[b]{2}{*}{.722} & \multirow{2}{*}{$\begin{array}{c}5.906 \\
10.321 \\
\end{array}$} & \multirow{2}{*}{$\begin{array}{l}.000 \\
.000 \\
\end{array}$} \\
\hline & .664 & .064 & & & \\
\hline & \multicolumn{5}{|c|}{ a. Dependent Variable: IM } \\
\hline \multicolumn{6}{|c|}{ Table-5: Regression summary } \\
\hline $\mathrm{R}$ & & .72 & & & \\
\hline R. squared' & & .52 & & & \\
\hline Adj. R squared' & & .56 & & & \\
\hline F-Value' & & & & & \\
\hline Sig. value' & & .00 & & & \\
\hline
\end{tabular}

\subsubsection{Regression between rewards system and extrinsic motivation}

The tables no. 6 and 7 demonstrates the results of the regression test that was undertaken to examine the validity of the second hypothesis of our study. Our second hypothesis, H2 proposed a positive relationship between Rewards System (RS) and Extrinsic Motivation (EM). The fitness value of the F value has been recorded at 97.50 which indicates that our proposed research model is fit. $\mathrm{R}$ square figure shows that a variance of $49.9 \%$ has been observed in the DV (Extrinsic Motivation) due to the independent variable (Rewards System). The significance value has been recorded at 0.000 which suggests that the results are significant. The beta value depicts that a one-unit change in Rewards System (RS) will lead to a 0.706 unit increase in Extrinsic Motivation (EM). Hence, a positive relationship linkage of two variables has been established. This finding is harmonious with our proposed hypothesis. Consequently, the second hypothesis, $\mathrm{H} 2$ is also accepted.

Table-6: Regression analysis of rewards system and extrinsic motivation

\begin{tabular}{|c|c|c|c|c|c|c|}
\hline \multicolumn{7}{|c|}{ Coefficients $^{\mathrm{a}}$} \\
\hline & \multirow{2}{*}{ Model } & \multicolumn{2}{|c|}{ Unstandardized coefficients } & \multirow{2}{*}{$\begin{array}{c}\text { Standardized } \\
\text { coefficients } \\
\text { Beta } \\
\end{array}$} & \multirow{2}{*}{$\mathrm{t}$} & \multirow{2}{*}{ Sig. } \\
\hline & & B & Std. Error & & & \\
\hline \multirow{2}{*}{1} & (Constant) & 1.692 & .358 & & 4.726 & .000 \\
\hline & RS & .678 & .069 & .706 & 9.874 & .000 \\
\hline
\end{tabular}

a. Dependent variable: EM 
Table-7: Regression summary

\begin{tabular}{ll}
\hline R & .706 \\
R. squared' & .499 \\
Adj. R squared' & .494 \\
F-Value' & 97.500 \\
Sig. value' & .000 \\
\hline
\end{tabular}

\section{Discussion and findings}

This study confirms that intrinsic motivation is associated with a reward system (H1). These results reflect those of Woolley and Fishbach (2018) who found that immediate reward increases intrinsic motivation. Furthermore, this finding is also consistent with the findings of Kuvaas et al. (2017).

This study further supports evidence for a relationship between the reward system and extrinsic motivation (H2). This result reflects those of Bear et al. (2017) who found that tangible rewards played a vital role in extrinsic motivation. These results may be explained by the fact that many researchers have argued that various types of rewards are associated with intrinsic and extrinsic motivation. However, the frequency and quality of motivation can be varied. Furthermore, it seems that motivational theories are a reliable tool to understand motivation. The findings of this research may exhibit cultural perspectives in motivation and reward system in the UAE. Hofstede (1980a) elaborated that Asian cultures have more power distance, masculine, and collective behaviour dimensions.

UAE is adopting new technologies and moving toward a knowledge-based economy. To stimulate and sustain this pace of innovation and development, high-performance work culture is required i.e., a culture in which the employees feel motivated both intrinsically and extrinsically and a culture that rewards the employee for their contributions, efforts, accomplishments, and hard work. To nurture such a culture, it is pertinent for the organizations to develop a comprehensive reward system that is aimed at enhancing the intrinsic and extrinsic motivation levels of the employees. For this purpose, the human resource professionals working in the organization need to analyze their existing reward mechanisms and identify the loopholes in the existing system that needs to be addressed.

On the other hand, it is equally important for the organizations to take into account the perspective of its employees with regards to their views and opinions regarding the organization's overall reward and motivation strategy. This can be achieved through conducting regular employee engagement surveys to gauge employee engagement and motivation levels. Such surveys can provide deep insight regarding the perception of the organization's employees towards the existing rewards and motivation strategy. Based on these surveys, the organization can take key and radical measures that are aimed at enhancing employee motivation levels. It is pertinent to mention that enhancing the intrinsic motivation of the employees is very crucial as indicated by the results of this study. The organization should identify ways in which it can boost the intrinsic motivation levels of its workforce. This can be achieved through several ways that include, getting to know the employees with regards to who they are and their wants, conducting a thorough analysis of the employee's work-life balance, tailoring the intrinsic motivation to the company-specific goals and objectives, laying utmost focus on the individual personalities of the employees, providing aid to the employee 
with regards to their respective careers by providing effective help and advice, and helping the employee to learn and grow professionally.

Extrinsic motivation also holds immense importance in order to enhance employee productivity and performance. Extrinsic motivation has been proven to arise as a result of external rewards. The employee feels extrinsically motivated when he/she feels that performing a certain task or job will get him/her a reward. Extrinsic motivation is not something that comes naturally rather it comes in the form of a reward that will be gained against completing a certain task. It is pertinent for the organizations to formulate a strategy that is aimed at fostering the extrinsic motivation levels of the employees. The organization should try to strike a balance between its extrinsic and intrinsic motivation strategy. To enhance the extrinsic motivation levels of the employees, the organization should draft and formulate a strategy that effectively rewards employees for their contributions and hard work. It can include money, praise, fame, and recognition.

\section{Conclusion}

The study examined relationship between reward system and intrinsic and extrinsic motivation of the employees within context of UAE. The investigation showed that reward system has a positive impact on intrinsic and extrinsic motivation. Furthermore, this investigation also complemented the earlier studies. The study has gone some way towards enhancing our understanding of phenomena in context of UAE. However, the scope of this study was limited in terms of sample size and context, so its finding cannot be generalized, further research is needed to understand the research agenda. Despite its limitations, the study certainly adds to our understanding of the reward system and extrinsic and extrinsic motivation. Further study could assess the long-term effects of reward systems on the quality and frequency of extrinsic and intrinsic motivation.

\section{References}

Ahmed, M. (2019). The sophistication of performance measurement system in manufacturing SMEs: The role of the interpersonal ties in top management teams. SSRN. https://dx.doi.org/10.2139/ssrn.3454614

Ajayi, S. (2019). Motivational drives and employee performance: Evidence from selected universities in Nigeria. SSRN. https://dx.doi.org/10.2139/ssrn.3335829

Allen, R. S., Takeda, M. B., White, C. S., \& Helms, M. M. (2004). Rewards and organizational performance in Japan and the United States: A comparison. Compensation \& Benefits Review, 36(1), 7-14. https://dx.doi.org/10.1177/0886368703261401

Armstrong, J. S. (Ed.). (2001). Principles of forecasting: A handbook for researchers and practitioners (Vol. 30). Springer Science \& Business Media.

Arokiasamy, A. R. A., Tat, H. H., \& Abdullah, A. (2013). The effects of reward system and motivation on job satisfaction: evidence from the education industry in Malaysia. World Applied Sciences Journal, 24(12), 1597-1604. https://citeseerx.ist.psu.edu/viewdoc/download?doi=10.1.1.571.2457\&rep=rep1\&type $=\mathrm{pdf}$

Asseburg, J., \& Homberg, F. (2018). Public service motivation or sector rewards? Two studies on the determinants of sector attraction. Review of Public Personnel Administration, 40(1), 82-111. https://dx.doi.org/10.1177/0734371x18778334 
Bear, G. G., Slaughter, J. C., Mantz, L. S., \& Farley-Ripple, E. (2017). Rewards, praise, and punitive consequences: Relations with intrinsic and extrinsic motivation. Teaching and Teacher Education, 65, 10-20. https://doi.org/10.1016/j.tate.2017.03.001

Bintoro, M. T. \& Daryanto. (2017). Manajemen penilaian kinerja karyawan. Gava Media.

Chen, C., Anchecta, K., Lee, Y.-D., \& Dahlgaard, J. J. (2016). A stepwise ISO-based TQM implementation approach using ISO 9001: 2015. Management and Production Engineering Review, 7(4), 65-75. http://dx.doi.org/10.1515/mper-2016-0037

Chepkemoi, J. \& Bett, S., (2018). Total quality management strategies and performance of institutions of higher learning in Kenya: Case of ISO certified public universities in Nairobi City County, Kenya. International Academic Journal of Human Resource and Business Administration, 3(3), 73-99. https://irlibrary.ku.ac.ke/bitstream/handle/123456789/21107/Total\%20quality\%20manageme nt\%20strategies\%20ISO....pdf?sequence $=1$

Clarity-Wave. (2019). Why Money is a Bad Motivator and What Works Better. https://www.claritywave.com/money-bad-motivator-works-better/

De-Vito, L., Brown, A., Bannister, B., Cianci, M., \& Mujtaba, B. G. (2016). Employee motivation based on the hierarchy of needs, expectancy and the two-factor theories applied with higher education employees. International Journal of Advancement in Management, Economics and Entrepreneurship (IJAMEE), 3(1), 20-32. http://www.ijamee.info/index.php/IJAMEE/article/view/37/35\#

Fernet, C., Austin, S., \& Vallerand, R. J. (2012). The effects of work motivation on employee exhaustion and commitment: An extension of the JD-R model. Work \& Stress, 26(3), 213-229. http://dx.doi.org/10.1080/02678373.2012.713202

Frey, B. S., \& Jegen, R. (2001). Motivation Crowding Theory. Journal of Economic Surveys, 15(5), 589-611. http://dx.doi.org/10.1111/1467-6419.00150

Herzberg, F. (1987, September 21). Workers' needs: The same around the world. Industry Week. https://www.coursehero.com/file/p6jj6lq/Herzberg-F-1987b-Workers-needsthe-same-around-the-world-Industrial-Week-Vol-29/

Hofstede, G. (1980a). Culture's consequences: International differences in work related values. Sage.

Ismail, A., \& Ahmed, S. (2015). Employee perceptions on reward/recognition and motivating factors: A comparison between Malaysia and UAE. American Journal of Economics, 5(2), 200-207. https://ssrn.com/abstract=2615322

Jansen, M. R. \& Hlongwane, P., (2019). Employee performance reward and recognition inequity in the Western Cape provincial department of transport and public works. International Conference on Public Administration and Development Alternatives (IPADA), Johannesburg, South Africa. http://ulspace.ul.ac.za/bitstream/handle/10386/2720/jansen_employee_2019.pdf?isAl lowed=y\&sequence $=1$

Jaskiewicz, A., \& Nowak, A. S. (2019). Constrained markov decision processes with expected total reward criteria. SIAM Journal on Control and Optimization, 57(5), 3118-3136. http://dx.doi.org/10.1137/19m1254829

Kalhoro, M., Jhatial, A. A., \& Khokhar, S. (2017). Investigating the influence of extrinsic and intrinsic motivation on work performance: Study of bank officers. Global Management Journal for Academic \& Corporate Studies (GMJACS), 7(1), 121-129. https://gmjacs.bahria.edu.pk/index.php/ojs/article/view/26

Kaplan, S. L. (2017). Business strategy, people strategy and total rewards. Benefits \& Compensation

Digest, 44(9),

12-19. 
http://www.staceykaplan.com/pdf/Stacey_Kaplan_Total_Rewards_And_Business_St rategy.pdf

Karell, E. \& Widlund, L. (2019). Rewarding work or working for reward? A qualitative case study about total rewards and work motivation among white-collar workers in Sweden. Master Thesis, University of Gothenburg. https://gupea.ub.gu.se/bitstream/2077/62505/1/gupea_2077_62505_1.pdf

Kubota. (2019). Kubota report 2019. https://www.kubota.com/report/pdf/report2019.pdf

Kokubun, K. (2018). Education, organizational commitment, and rewards within Japanese manufacturing companies in China. Employee Relations, 40(3), 458-485. http://dx.doi.org/10.1108/er-12-2016-0246

Kuvaas, B., Buch, R., Weibel, A., Dysvik, A., \& Nerstad, C. G. L. (2017). Do intrinsic and extrinsic motivation relate differently to employee outcomes? Journal of Economic Psychology, 61, 244-258. https://doi.org/10.1016/j.joep.2017.05.004

Malik, M. A. R., Choi, J. N., \& Butt, A. N. (2019). Distinct effects of intrinsic motivation and extrinsic rewards on radical and incremental creativity: The moderating role of goal orientations. Journal of Organizational Behavior, 40(9-10), 1013-1026. https://doi.org/10.1002/job.2403

Mantere, S. (2007). Role Expectations and Middle Manager Strategic Agency. Journal of Management Studies, 45(2), 294-316. https://doi.org/10.1111/j.14676486.2007.00744.x

Nawaz, M., Makhdoom, T. R., \& Baloch, N. (2017). Antecedent of student citizenship behaviours (SCB) within Pakistani higher educational context. European Journal of Business and Social Sciences, 6(1), 165-175. https://scholar.google.com/scholar?cluster=13869784295927371306\&hl=en\&as_sdt $=0,5$

Nelson, B. (1994). 1001 ways to reward employees. Workman Publishing.

Newman, A., \& Sheikh, A. Z. (2012). Organizational rewards and employee commitment: a Chinese study. Journal of Managerial Psychology, 27(1), 71-89. https://doi.org/10.1108/02683941211193866

Ngwa, W. T., Adeleke, B. S., Agbaeze, E. K., Ghasi, N. C., \& Imhanrenialena, B. O., (2019). Effect of reward system on employee performance among selected manufacturing firms in the Litoral region of Cameroon. Academy of Strategic Management Journal, $18(3)$, $1-16$. https://search.proquest.com/openview/ca48ee7175f706294cd9f71dd8298f78/1?pqorigsite $=$ gscholar $\& \mathrm{cbl}=38745$

O’Driscoll, M. P., \& Randall, D. M. (1999). Perceived organisational support, satisfaction with rewards, and employee job involvement and organisational commitment. Applied Psychology, 48(2), 197-209. https://doi.org/10.1111/j.1464-0597.1999.tb00058.x

Okello, G.A. (2018). Influence of reward philosophy on the growth of micro and small furniture manufacturing enterprises in Kenya. International Academic Journal of Human Resource and Business Administration, 3(3), 333-355. http://iajournals.org/articles/iajhrba_v3_i3 333 355.pdf

O'Reilly, C. A. (1991). Organizational behaviour: Where we've been, where we're going. Annual Review of Psychology, 42(1), 427-458. https://www.annualreviews.org/doi/abs/10.1146/annurev.ps.42.020191.002235

Pink, D. H. (2011). Drive: The surprising truth about what motivates us. Penguin.

Raghavendra, A. N. \& Vijayakumar, G. (2020). Winning employees for work motivation through effective reward management. Studies in Indian Place Names, 40(18), 60-71. 
Roscoe, J. T. (1975). Fundamental research statistics for the behavioural sciences. Holt, Rinehart and Winsto.

Ryan, R. M., \& Deci, E. L. (2020). Intrinsic and extrinsic motivation from a self-determination theory perspective: Definitions, theory, practices, and future directions. Contemporary Educational Psychology, 61, 101860. https://doi.org/10.1016/j.cedpsych.2020.101860

Sajjad, A., Ghazanfar, H. \& Ramzan, M. (2013). Impact of motivation on employee turnover in telecom sector of Pakistan. Journal of Business Studies Quarterly, 5(1), 76-92. https://citeseerx.ist.psu.edu/viewdoc/download?doi=10.1.1.653.1358\&rep=rep1\&typ $\mathrm{e}=\mathrm{pdf}$

Shamir, B. (1991). Meaning, self and motivation in organizations. Organization Studies, 12(3), 405-424. https://doi.org/10.1177/017084069101200304

Sharma, S. (2019). Extrinsic rewards, occupational commitment, career entrenchment and career satisfaction of dentists. Asia Pacific Journal of Health Management, 14(1), 113. https://doi.org/10.24083/apjhm.v14i1.221

Sureephong, P., Dahlan, W., Chernbumroong, S., \& Tongpaeng, Y. (2020). The effect of nonmonetary rewards on employee performance in massive open online courses. International Journal of Emerging Technologies in Learning (IJET), 15(1), 88-102. https://doi.org/10.3991/ijet.v15i01.11470

Tremblay, M. A., Blanchard, C. M., Taylor, S., Pelletier, L. G., \& Villeneuve, M. (2009). Work extrinsic and intrinsic motivation scale: Its value for organizational psychology research. Canadian Journal of Behavioural Science / Revue Canadienne des sciences du comportement, 41(4), 213-226. https://doi.org/10.1037/a0015167

Vouzas, F., \& Katsogianni, T. (2018). TQM implementation in 3PL organisations vs organisations with in-house logistics department: A literature review. The TQM Journal, 30(6), 749-763. https://doi.org/10.1108/tqm-10-2017-0115

Williams, S., \& Shiaw, W. T. (1999). Mood and organizational citizenship behaviour: The effects of positive affect on employee organizational citizenship behaviour intentions. The Journal of Psychology, 133(6), 656-668. https://doi.org/10.1080/00223989909599771

Wright, B. E. (2007). Public service and motivation: Does mission matter? Public Administration Review, 67(1), 54-64. $\quad$ https://doi.org/10.1111/j.1540$\underline{6210.2006 .00696 . x}$

Woolley, K., \& Fishbach, A. (2018). It's about time: Earlier rewards increase intrinsic motivation. Journal of Personality and Social Psychology, 114(6), 877890. https://doi.org/10.1037/pspa0000116 


\section{Annexure 1:}

Section A: Personal profile
1. Gender:
a) Male
b) Female

2. Qualification:
a) Below $12^{\text {th }}$ grade
b) Undergraduate
c) Post-graduate
d) Diploma

3. Experience:
a) 1-5 years
b) 5 to 10 years
c) 10 to 15 years
d) $15+$ years

4. Level of organization:
a) Non-management
b) Lower-management
c) Middle-management
d) Top-management

\begin{tabular}{|c|c|c|c|c|c|c|c|c|}
\hline $\begin{array}{l}\text { S. } \\
\# .\end{array}$ & Question statement & 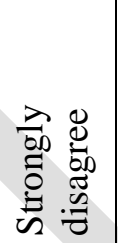 & 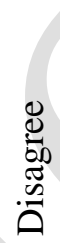 & 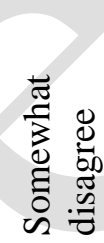 & 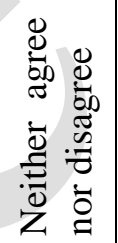 & 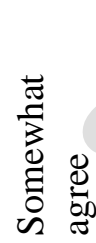 & $\begin{array}{l}8 \\
\stackrel{0}{0} \\
\ll\end{array}$ & 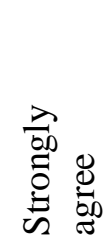 \\
\hline
\end{tabular}

Section B: Reward system

1 I have awareness of a reward system in my organisation.

2 All the employees in your organisation eligible for reward as per company policy

3 The reward/ recognition have positive effect to the work atmosphere

4 The reward from management matches my work efforts

5 Rewards are important to achieve goals

Section C: Intrinsic motivation

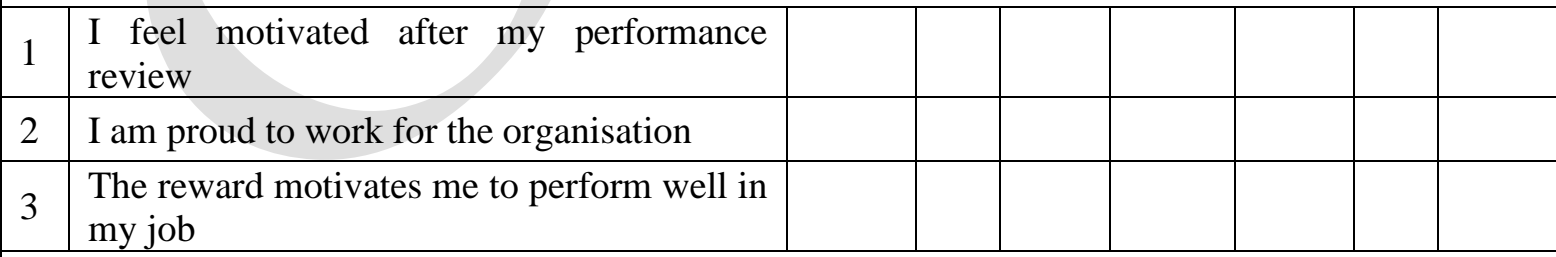

Section D: Extrinsic motivation

1 There is a possibility of promotion and growth in the organisation.

2 Performance appraisal activities are helpful to get motivated

3 The management is interested in motivating the employee. 